\title{
Research on the Cultivation of Application-oriented Architecture Talents in Computer 3D Representation
}

\author{
Shaoju Hao \\ Henan Radio and Television University \\ Zhengzhou, China
}

\author{
Hansong Yang \\ Huanghe Science and Technology College \\ Zhengzhou, China
}

\begin{abstract}
The application-oriented architecture major should put emphasis on the cultivation of students' ability of practice and in this article, it analyzes the necessary for students of architecture major to learn computer 3D architectural expression, puts forwards the integration of curriculum content designing and student employment, as well as encourages students to participate in related competition, developing their thoughts and promoting their practical and innovative ability.
\end{abstract}

Keywords-3D architectural expression; application-oriented; talent cultivation

\section{INTRODUCTION}

Along with the deepening of popularization higher education in China as well as the repaid development of vocational college with prominent features of applicationoriented talent cultivation, the cultivation of practical ability plays more and more important role on students of architecture major in application-oriented vocational college.

The expression mode of traditional design drawing includes two aspects in normal: architectural drawing and architectural model. There are various expression modes for architectural drawing, including pencil drawing, pen drawing, bone-line wash drawing, watercolor, gouache, air-brush and mark drawing etc. all of which have their own characteristics and can conduct expression based on different requirements. Architectural model is the only form taking real object to express architectural design, one of the most forceful means of architectural design expression and it is the microform of completed construction that the viewers can watch the shape, space, texture, color and the external environment of the building. With the rapid development of science and technology, the tools and materials for making model progress with each passing day, while the relative cost is much larger in regular teaching. In the wake of popularity of computers, the design drawing software has more and more functions and correspondingly the usage becomes easier. The traditional architecture expression drawing is rarely used in the final normal expression drawing, instead of the architecture rendering sketch, animated drawing and virtual reality etc. Related computer 3D expression software application is required by employer when students of architecture major of application-oriented university are applying for a job. Hence, it is necessary for students of architecture major to learn computer 3D architectural expression.
In the face of the reality that students at the present stage have poor absorbing ability on discipline system knowledge while have good visual thinking ability on practical operation, the 3D CAD course, as a core course of architecture major, the content of which should be in close touch with the practical work contents, at the same time focus on knowledge in working process in teaching, emphasize the significance of normally drawing, adopting task-driven method, demonstration method, independent study method, discussion method and other teaching methods to conduct classroom teaching, so that students can learn from practice and experience work in learning, cultivating them with good vocational ability and professionalism. Reflecting the 3D CAD course of traditional architecture major having poor teaching effect, cannot reach the requirements of employer.

\section{COMPUTER-AIDED DESIGN SOFTWARE INTRODUCTION}

Computer-aided design software mainly includes of AutoCAD 、 3dsMax 、 SketchUP 、 Photoshop and other software. AutoCAD belongs to engineering drawing software, although 3D modeling function is not its advantage while in current kindred software, it is the indisputable basic software for $3 \mathrm{~d}$ modeling in domestic architecture circles or even engineering design circles[2]. AutoCAD renews so fast that one new version will be issued for each year, relatively the same with its secondary development software. It is necessary to popularize AutoCAD and 3dsMax software to students in regular teaching. Photoshop, which is a professional image processing software issued by Adobe company, well received by image processing personnel and graphic designers due to its strong image processing \& editing function as well as faultless color expression. In consideration of its simple and easylearning operation, true and perfect texture mapping as well as abundant and multiple colors, it rapidly permeates architectural design and planning design industries [3].

\section{TAKE THE OPPORTUNITY AND OPEN COMPUTER 3D ARCHITECTURE EXPRESSION COURSE}

The main problems existing in traditional 3D CAD course are: first is the disconnection between the content of 3D CAD course and practical work, having poor pertinence to the course contents. For students of architecture major in normal school, their main job in future is draftsman, content of which is to do construction drawings. While the traditional 3D CAD course content complying with construction technology and 
construction costs, only focuses on the universality of public ability of architecture major in content and requires the students to grasp usage of orders as well as have the ability of drawing construction drawings instead of highlighting the professionalism of architecture major. For contents, architectural construction drawing mainly reflects the total layout, external shape, internal separation, construction structure etc. while decoration construction drawing mainly reflects the decoration structure, modeling disposal, decorating method as well as layout of furniture and furnishings of the three interfaces of wall, floor and roof; for requirements, the construction drawing refers to Unified Standard for Building Drawing, while drawing decoration construction drawing refers to Design Standard for Interior Design Construction Drawing. In addition, there are lots of differences between them, such as drawing technology, drawing layout way and industrial practice. Moreover, with respect to the students with poor transfer ability of knowledge, it is really hard for them to realize the transition from construction drawing to decoration construction drawing, which the college should help with. In the writer's opinion, the college should teach decoration construction drawing in depth based on 3D CAD course instead of replacing decoration knowledge with 3D CAD directly.

The structure of course content is unreasonable that the traditional 3D CAD course is with guidance of orders and layout in order of knowledge law, that is, learn functions, operation methods of single order of 3D CAD software etc. knowledge points in prior, and then makes students to complete architecture drawing. Knowledge and application are completely separated by this layout of discrete teaching content. Superficially, students can learn the entire knowledge while facing actual construction drawing task, they are confused with what to draw first, by which order and which method successively. The connection is not closely between the knowledge of its content structure and application and does not meet the students' cognition order as well as ability forming law. 3D CAD course also is lack of attention on professionalism. Moreover, there are two very important core tasks of 3D CAD course: the first is the training on the professional ability of quick and accurate computer drawing ability etc.; the second is to take the professional ability training process as carrier and conduct cultivation on the formation of students' practical work attitude as well as work "particularities", in order of cognition, feelings, practice, experience, internalization and the formation of professionalism.

\section{REASONABLE ORGANIZATION OF THE TEACHING CONTENT OF COMPUTER 3D ARCHITECTURAL EXPRESSION COURSE}

There are lots of computer 3D architectural expression softwares, so that it is necessary to give careful consideration on choosing which kind of software while teaching. The making process of architectural effect picture can be divided into six steps: early preparation, 3D modeling, and material deploy, lights and camera arrangement, scene rendering and post-processing. For one piece of effect picture, 3D modeling occupies more than half workload of it. After research on design institute of architecture and planning as well as numbers of effect picture companies, it shows that more companies use 3dsMax software, so that it is necessary to adopt AutoCAD for 2D drawing, introducing some 3D drawing technologies, then lead AutoCAD 2D picture into 3dsMax for 3D modeling and light material treatment as well as introduce Photoshop software application simply while making teaching plan. The content of the course should focus on the introduction of 3dsMax application, including basic knowledge of 3dsMax, basic modeling, modifier modeling, compound object modeling as well as introduction of light materials. While teaching, in order to integrate theory and practice, it is necessary for them to learn in computer room by small class model, which can guarantee the students learn while practicing, grasping related orders and technologies fast. After the completion of learning, to help the students go to companies of architectural expressions for practice in winter and summer vacation will improve their practical ability better.

With respect to class hour arrangement, refine the whole teaching content of 36 hours into three phases: take 2 hours to review AutoCAD 2D drawing knowledge as well as the way to lead CAD into 3dsMax, 30 hours to learn 3dsMax modeling and 4 hours to introduce post-processing knowledge of Photoshop. For 30 hours of 3dsMax modeling in total, take 4 hours using for basic knowledge learning, including the introduction of view operation, interface customization, selection and management of the objective as well as transform tools. During learning basic knowledge, students can build some simple models to grasp the usage of hotkeys; moreover, take 8 class hours on Chapter II to introduce the basic orders of 3dsMax, particularly in grasping the orders of aligning, mirror image, array, stack, spline editing, extrude and chamfer; take 12 class hours on Chapter III to introduce 3dsMax modifier modeling, in particular of Chamfer Profile, FFD Transformer, Bending, Turnery, Frame, Cap holes, Normal, Smooth and Edit Mesh modifier; at last, take 6 class hours to introduce how 3dsMax can render a picture. All mentioned class hours include practical teaching, means of which mainly compose of actual computer operation and working practice.

With respect to course assessment, performance of which composes of usual performance and final performance and the final examination requires the students to complete the modeling, rendering and post-treatment of one architectural unit in cooperative group of 3 to 4 members and the students can, at his own decision, complete any section in modeling, rendering and post-treatment. The performance will be given based on its complete effect.

\section{Cultivation on Practical Ability of Students COMBINED WITH COMPETITION}

The knowledge we learn in school in limited, so that the teachers should organize more student competition and encourage the students to participate. Through student competition to enhance students' interest in learning and promote communication with students of other colleges, in which way, they will find out their weaknesses and make a steppingstone to their employment in future. The teachers can also organize the students to participate "high-education cup", 
"3D Competition" and other student competition which mainly test students' computer-aided drawing ability. After their participation, the students gain quite a lot experience and successively show their determination of study to enrich their knowledge structure. After all, only a few of students participate the student competition, in order to share their competition experience to more students, the college also organizes related competition experience sharing meeting introducing the knowledge they learned from the competition to students by the attended students and instructor, so as to encourage more students to take part in for urging learning and application by competition. Moreover, some competitions are link up with employers, the students who make outstanding expression can sign the employment agreement with the employer, which is good for the students.

In conclusion, the computer $3 \mathrm{D}$ architectural expression is a professional technical ability course with very strong practicality involving not only knowledge of its own major, but also knowledge of computer software and hardware aspects, which requires, with the rapid development of science and technology, the teachers should have abundant knowledge structure and struggle for cultivating applied talents with vocational skills by guiding the students to learn in reasonable and effective ways.

\section{REFERENCES}

[1] Y.F. Wang,L. Yan, J. Li. Reform and exploration in the teaching of CAD Auto. Chemical Engineering \& Equipment.2015 Vol. 29.

[2] L. P. Liu, H. Ye.Techniques and applications of AutoCAD graphics in Teaching. Computer Knowledge and Technology.2015 Vol. 33

[3] X. L. Li, T. H. Duan. Research on the teaching of AutoCAD courses combined with professional application. Education Teaching Forum. 2015 Vol. 14.

[4] Q. ZH. Wu. Talking about the teaching reform of architectural CAD course. Shanxi Architecture.2014 Vol. 15.

[5] X. Y. Yang. Application analysis of architectural drawing based on AutoCAD. Electronic Test. 2014 Vol. 18. 